\title{
Estudo do crescimento e qualidade de mudas de marupá (Simarouba amara Aubl.) em viveiro
}

\author{
Isabel Maria Gonçalves de AZEVEDOํ, Ramilla Machado de ALENCAR², Antenor Pereira BARBOSA³, \\ Narrúbia Oliveira de ALMEIDA ${ }^{4}$ \\ RESUMO
}

O objetivo do trabalho foi avaliar o crescimento e a qualidade das mudas de marupá com o sistema radicular podado em diferentes sombreamentos. O experimento foi instalado na Estação Experimental de Silvicultura Tropical do INPA, em Manaus (AM), situada na rodovia BR-174, km 43. As sementes foram beneficiadas e semeadas a $1 \mathrm{~cm}$ de profundidade em areia lavada. As mudas foram repicadas para sacos plásticos contendo 3 partes de terra de subsolo, 1 de areia, 0,5 de esterco de galinha curtido. Após as podas das raízes em $0 \%, 25 \%, 50 \%$ e 75\% as mudas permaneceram por 30 dias sob galpão, irrigadas diariamente e depois levadas para canteiros cobertos com telas sombrite de 30\%, 50\%, 70\% e 0\% (sem sobreamento). Cada parcela continha 35 mudas incluindo bordadura simples. Foram avaliadas 5 mudas (repetiçóes) ao acaso aos 57,139 e 182 dias em viveiro. Os dados foram analisados por fatorial 4 x 4 na primeira e 3 x 4 nas outras mediçóes. Foi estudada a altura total (HT), diâmetro do colo (DC), número de folhas, área foliar, pesos da matéria seca de raiz, caule e folhas e a qualidade das mudas pelo Índice de Qualidade de Dickson e pela relação HT/DC. As mudas foram atacadas por lagartas nos canteiros sem sombreamento e a sobrevivência foi superior a $83 \%$ naquelas sombreadas. As mudas resistiram às podas e, aos 182 dias, apresentaram maior qualidade para plantios e com maior equilíbrio de crescimento sob sombreamento de $50 \%$.

PALAVRAS-CHAVE: Espécie florestal, Silvicultura, Reflorestamento, Espécie nativa da amazônia e Espécie pioneira.

\section{Study of growth and quality of marupá (Simarouba amara Aubl.) nursery seedlings}

\section{ABSTRACT}

Our objective was to evaluate the growth and quality of marupá (Simarouba amara Aubl.) seedlings with root system pruning in different shadings. The experiment was undertaken at the INPA Tropical Forestry Experimental Station, in Manaus (AM), located at highway BR-174, $\mathrm{km}$ 43. The seeds were processed and sown at a depth of $1 \mathrm{~cm}$ in washed sand. The seedlings were transplanted to plastic bags containing 3 parts subsoil, 1 sand, and 0.5 chicken manure fertilizer. After pruning their roots at $0 \%, 25 \%, 50 \%$ and $75 \%$, for 30 days the seedlings remained under the shed, irrigated daily and then planted in beds covered with screens of $30 \%, 50 \%, 70 \%$ and $0 \%$ ( without shading). Each plot contained 35 seedlings including simple edge. Five seedlings (repetitions) were assessed at random at 57, 139 and 182 days in nurseries. The data were analyzed by factorial $4 \mathrm{x}$ 4 in the first and $3 \times 4$ in the other measurements. We studied the total height (HT), diameter of the colon (DC), number of leaves, leaf area, dry weight of roots, stems and leaves of the seedlings, the quality index of Dickson, and the relationship HT/ DC. The seedlings were attacked by caterpillars in beds without shading and survival was over $83 \%$ in shaded beds. The seedlings survived pruning, and at 182 days, showed higher quality for plantations, and better growth balanceunder $50 \%$ shade.

KEYWORDS: Forest species, Silviculture, Reforestation, native Amazon species and Pioneer species.

\footnotetext{
1 Universidade Federal do Amazonas. E-mail: isa_florestal@yahoo.com.br

2 Universidade Federal do Amazonas. E-mail: milla-alencar@hotmail.com

3 Instituto Nacional de Pesquisas da Amazônia. E-mail: antenor@inpa.gov.br

${ }^{4}$ Universidade Federal do Amazonas. E-mail: nalmeida@ufam.edu.br
} 


\section{INTRODUÇÃO}

O marupá (Simarouba amara Aubl.- Simaroubaceae) ocorre nas Índias Ocidentais, na Amazônia e nos Estados da Bahia, Ceará e Pernambuco. A espécie habita matas de várzeas, onde é mais frequente e atinge maior porte, e é ocasional nas capoeiras e savanas de solo arenoso. A madeira é leve (0, 435 a $\left.0,55 \mathrm{~g} / \mathrm{cm}^{3}\right)$, fácil de trabalhar e muito resistente ao ataque de insetos (Loureiro, 1979).

A madeira de marupá é recomendada para utilização em ambientes externos, tais como construção civil e naval, pontes, etc (IBDF, 1983; Souza, 1997). Pois é fácil de serrar, aplainar, pregar e aparafusar, recebendo bom acabamento (Cavalcante, 2006).

A madeira também é indicada para confecção de tampo de instrumento musical de corda (Slooten e Souza 1993). Nos Estados Unidos é utilizada para tubos de órgãos e teclas de pianos (Marques et al., 2006) .

Além disso, cita-se vários usos e serviços do marupá como para lenha e carvão, madeira comercial, cerca viva, planta medicinal, sombra e artesanal (Franke, 1999 e Costa et al., 2006) .

Quanto a fenologia é uma espécie de padrão regular, com plena floraçáo no mês de dezembro, no início da estação chuvosa e a frutificação na estaçáo chuvosa (Pinto et al., 2005). Isto favorece o semeio e a produção de mudas na região amazônica.

Segundo Cruz et al. (2006) vários fatores afetam a qualidade de mudas, dentre eles a qualidade da semente, tipo de recipiente, substrato, adubaçẫo e manejo das mudas em geral.

A formaçấo de mudas mais vigorosas permite maior chance de sucesso no estabelecimento da cultura, bem como maximiza seu crescimento ao diminuir o tempo de transplante para o campo (Lima et al., 2008).

A luz, por ser fonte primária de energia está relacionada à fotossíntese (Campos e Uchida, 2002). Segundo Lima et al. (2008) é um dos principais fatores que influencia o crescimento e o desenvolvimento dos vegetais.

No estudo de Barbosa et al. (1998) com diferentes níveis de sombreamento, concluiu-se que o tratamento com $70 \%$ de sombra foi excessivo, inclusive para as espécies consideradas intermediárias ou clímax e que as espéceis pioneiras tenderam a tolerar um baixo ou nenhum sombreamento.

Mudas de Jacaranda puberula Cham. (caroba), num período de 8 meses em viveiro, alcançaram maior crescimento em todas as variáveis, no tratamento com $30 \%$ de sombreamento, em relação as mudas dos tramentos 50\% e 70\% (Almeida et al., 2005).
O estudo de Barbosa et al. (1990) sobre diferentes níveis de sombreamento $(0,30,50$ e $70 \%)$ e espaçamento em viveiro $(10 \mathrm{x} 10,14 \mathrm{x} 14$ e $18 \times 19 \mathrm{~cm})$ no período de seis meses em mudas de caroba (Jacaranda copaia), embora esses fatores não tenham apresentado diferença estatística, os níveis de maior sombreamento e espaçamento tiveram valores superiores. Da mesma forma, o crescimento em altura de mudas de cumaru (Dipteryx odorata) não foi influenciado pelos níveis de sombreamento (Uchida e Campos, 2000).

Porém, Scalon et al. (2003) para mudas de Bombacopsis glabra (castanha-do-maranhão) verificaram que somente a altura apresentou diferença quanto à disponibilidade da luz, sendo maior sob $50 \%$ de sombreamento $(22,30 \mathrm{~cm})$, seguida de $30 \%(18,90 \mathrm{~cm})$ e em pleno sol $(15,80 \mathrm{~cm})$. Varela e Santos (1992) concluíram que na produção de mudas de angelim pedra (Dinizia excelsa) nos níveis de sombreamento 30 e $50 \%$ proporcionaram maior altura $(35,56 \mathrm{~cm})$ em relação ao de $70 \%(29,94 \mathrm{~cm})$.

Para mudas de Caesalpinia ferrea submetidas a diferentes intensidades de luz, as análises de variáveis biométricas indicaram que o tratamento a pleno sol propiciou melhores condições para o crescimento e desenvolvimento dessa espécie (Lima et al., 2008).

Quanto as práticas culturais que também podem otimizar a produção de mudas com melhores características morfológicas e fisiológicas para uma melhor sobrevivência no campo, podemos citar a prática de poda das raízes.

A realização da poda do sistema radicial das mudas permite o aumento da emissão de novas raízes, pois de cada extremidade de raiz podada pode ocorrer emissão de duas ou mais raízes novas, o que permite maior contato com o solo, favorecendo a aquisição de nutrientes e água (Freitas et al., 2009).

A poda do sistema radicial das mudas no viveiro também pode beneficiar a aquisição de nutrientes que têm baixa mobilidade no solo, como é o caso do fósforo, que é um dos elementos necessários para o crescimento inicial das mudas no campo. Além de prolongar o período da muda dentro do viveiro sem causar danos às mudas como deformaçóes nas raízes por falta de espaço, evitando que as mudas percam sua qualidade, pois há uma paralisaçấo no crescimento das mudas durante um tempo até que ela retome o seu crescimento (Freitas et al., 2009).

No estudo de Barbosa et al.(1998) as podas de raiz foram toleradas e estimularam o crescimento do sistema radicular, com exceção do nível de $75 \%$ do sistema radicular que foi excessivo para algumas espécies.

Em mudas de eucalipto (Eucaliptus grandis) sob tratamento de podas mais leves, as raízes que permaneceram foram capazes de manter ou elevar a absorção de água e nutrientes 
de tal modo que a planta cresceu mais que as sem poda e o lançamento de novas raízes foi mais rápido. Entretanto, nos níveis mais intensos, por algum período, causaram estagnação no crescimento e o lançamento de novas raízes foi lento (Alvarenga et al., 1994).

As podas realizadas aos 50, 60, e 70 dias após a germinação de Prosopis juliflora (algarobeira) também estimularam o desenvolvimento de raízes secundárias (Souza et al., 2006).

A produção de mudas de eucalipto (Eucalyptus camaldulensis e Eucalyptus urophylla) em diferentes recipientes e podadas lateralmente a $2 \mathrm{~cm}$ da raiz pivotante, alcançaram melhores resultados quanto ao potencial de regeneração de raízes em mudas produzidas em blocos prensados, pois as plantas mostraram-se mais vigorosas e áptas para uma maior exploração de água e nutrientes no sítio de plantio, em relação às produzidas em tubetes (Barroso et al., 2000).

A altura e o diâmetro de mudas de Eucalyptus camaldulensis não apresentaram diferença do crescimento entre os tratamentos de poda, mas as mudas apresentaram maior comprimento e diâmetros de raízes produzidas, quando sofreram duas podas durante o ciclo de produção (Freitas et al., 2009).

Este trabalho teve como objetivo gerar informações silviculturais básicas para o cultivo de espécies florestais nativas da Amazônia, testando a resistência das mudas de marupá às podas de raiz e estudar o crescimento sob diferentes sombreamentos através da biometria e dos parâmetros de qualidade de mudas em viveiro.

\section{MATERIAL E MÉTODOS}

O experimento foi instalado no viveiro da Estação Experimental de Silvicultura Tropical (EEST) do INPA, em Manaus, estado do Amazonas, situada na rodovia BR-174, km 43 e com coordenadas geográficas de 2०35’00" S e 60²0’00” W, obtidas com GPS - SAD69.

O clima da EEST, segundo classificação de Koppen é do tipo $\mathrm{Am}$, com temperatura média anual de $26,7^{\circ} \mathrm{C}$, máximas de $31,4^{\circ} \mathrm{C}$ e mínimas de $23,3^{\circ} \mathrm{C}$. Os solos predominantes são Latossolo Amarelo e Podzólico Vermelho-Amarelo de textura argilosa (Ranzani, 1980).

As sementes de marupá foram coletadas de uma matriz da EEST, beneficiadas e semeadas a $1 \mathrm{~cm}$ de profundidade, em caixas de germinação contendo areia lavada.

A repicagem foi feita em sacos plásticos de polietileno pretos $(15 \times 26 \mathrm{~cm})$, contendo substrato composto por 3 partes de terra de subsolo (terra argilosa - horizonte B), 1 parte de areia, 0,5 parte de esterco de galinha curtido e com plântulas de $10 \mathrm{~cm}$ de altura em média.
As podas de raiz em $0 \%, 25 \%, 50 \%$ e $75 \%$ do comprimento total do sistema radicular, foram feitas no momento da repicagem e as mudas permaneceram por 30 dias, sob galpão e com duas irrigaçóes diárias por aspersão. Em seguida, foram transportadas para os canteiros cobertos por cima e pelas laterais com telas de poliolefina pretas (sombrite) graduadas pelo fabricante em 30\%, 50\% e 70\% de sombreamento. O canteiro do tratamento ( $0 \%$ sombreamento) náo recebeu sombrite.

Cada parcela do experimento foi composta por 35 mudas distribuídas em 5 filas de 7 mudas com bordadura simples. Em cada avaliação foram retiradas 5 mudas (repetiçóes) ao acaso e as restantes re-arrumadas para manter a distância entre as plantas e a bordadura.

O delineamento estatístico utilizado foi o inteiramente ao acaso e as mediçóes feitas aos 57, 139 e 182 dias em viveiro. Os dados foram analisados em esquema fatorial (4 x 4) na primeira medição e $(3 \times 4)$ nas outras medições em conseqüência da alta mortalidade que ocorreu no tratamento $0 \%$ de sombreamento.

O crescimento das mudas de marupá foi estudado através das mediçóes da altura total (HT), diâmetro do colo (DC), número de folhas $(\mathrm{NF})$, área foliar $(\mathrm{AF})$, pesos da matéria seca de raiz (PSR), caule (PSC) e folhas (PSF) e a qualidade das mudas calculada pelo Índice de Qualidade de Dickson $(\mathrm{IQD}=\mathrm{PMST} /[(\mathrm{HT} / \mathrm{DC})+(\mathrm{PMSPA} / \mathrm{PMSR})])$, segundo Dickson et al. (1960) citado por Fonseca et al. (2002) e pela relação HT/DC (Carneiro, 1995). A porcentagem de sobrevivência foi avaliada com base no número de mudas no início e no final do experimento (Scalon, 2003).

\section{RESULTADOS E DISCUSSÃO}

Aos 57 dias em viveiro foi observado intenso ataque de lagartas nas folhas das mudas de marupá com $0 \%$ de sombreamento, o que reduziu a sobrevivência em todos os tratamentos de poda. Nas avaliaçóes seguintes, a sobrevivência foi zero no canteiro sem sombreamento. Nos outros tratamentos a sobrevivência variou de 83 a $100 \%$ até o final do experimento. Esses resultados mostram que o sombrite em viveiro também protege as mudas quando colocado nas laterais e por cima dos canteiros.

Almeida et al. (2005), também observaram alta mortalidade em mudas de caroba (Jacaranda puberula) sob $0 \%$ de sombreamento o que inviabilizou as avaliaçóes nesse tratamento, no entanto náo identificaram a causa da baixa sobrevivência.

No estudo de Scalon et al. (2003) sobre o crescimento de mudas de castanha-do-maranhão (Bombacopsis glabra) a sobrevivência não foi influenciada pelos níveis de sombreamento de 0\%, 30\% e 50\%. Mas, Chaves e Paiva 
(2004) concluíram que a sobrevivência de mudas de fedegoso (Senna macranthera) apresentou aumento com o período de sombreamento a $50 \%$.

As podas das raízes não produziram diferenças na altura, diâmetro, número de folhas e área foliar em todos os períodos observados. O que evidencia uma recuperaçáo do sistema radicular podado para manter a sobrevivência e o crescimento da parte aérea, contudo houve diferentes respostas aos níveis de sombreamento (Tabela 1). Em algarobeira (Prosopis juliflora), as podas do sistema radicular estimularam o desenvolvimento de outras raízes (Souza et al., 2006).

Barbosa et al. (1998) verificaram que em mudas de 8 espécies florestais nativas da amazônia, as podas de raiz estimularam o crescimento do sistema radicular, com exceção do nível $75 \%$ de poda radicular que foi excessivo para algumas delas.

Alvarenga et al. (1994) observaram que as mudas de eucalipto (Eucaliptus grandis) com podas mais leves, as raízes que permaneceram foram capazes de manter ou elevar a absorçâo de água e nutrientes de tal modo que a planta cresceu mais que as sem poda e o lançamento de novas raízes foi mais rápido. Porém, os níveis de poda mais intensos, por algum período, causaram estagnaçáo no crescimento das plantas e o lançamento de novas raízes foi lento.

O potencial de regeneração de raízes é um parâmetro fisiológico, considerado por Novaes et al. (2002), como confiável na determinaçáo da qualidade de mudas de Pinus taeda e na previsão do desempenho no campo.

No entanto, essas variáveis foram influenciadas pelos sombreamentos e na primeira avaliaçáo (57 dias) a altura foi maior nos tratamentos com maior sombreamento $(50 \mathrm{e}$ $70 \%$ ) quando comparados com o de $0 \%$. Aos 139 dias não ocorreram diferenças, mas aos 182 dias a altura foi maior nos canteiros com sombreamentos de 30 e 50\% (Tabela 1).

Tabela 1 - Valores médios da altura (HT), diâmetro do colo (DC), número de folhas (NF) e área foliar (AF) de mudas de marupá (Simarouba amara Aubl.) cultivadas em diferentes sombreamentos.

\begin{tabular}{lccccc}
\hline Dias no viveiro & $\begin{array}{c}\text { Sombra } \\
(\%)\end{array}$ & $\mathrm{HT}(\mathrm{cm})$ & $\mathrm{DC}(\mathrm{mm})$ & $\mathrm{NF}$ & $\begin{array}{c}\mathrm{AF} \\
\left(\mathrm{dm}^{2}\right)\end{array}$ \\
\hline \multirow{4}{*}{57} & 0 & $14,50 \mathrm{~b}$ & $3,44 \mathrm{c}$ & $4,68 \mathrm{~b}$ & $0,14 \mathrm{~b}$ \\
& 30 & $17,33 \mathrm{ab}$ & $4,85 \mathrm{a}$ & $11,60 \mathrm{a}$ & $2,39 \mathrm{a}$ \\
& 50 & $18,02 \mathrm{a}$ & $4,61 \mathrm{ab}$ & $10,25 \mathrm{a}$ & $2,39 \mathrm{a}$ \\
\hline \multirow{3}{*}{139} & 70 & $18,75 \mathrm{a}$ & $4,25 \mathrm{~b}$ & $9,95 \mathrm{a}$ & $2,14 \mathrm{a}$ \\
\hline & 30 & $20,14 \mathrm{a}$ & $4,67 \mathrm{~b}$ & $11,96 \mathrm{a}$ & $2,74 \mathrm{ab}$ \\
& 50 & $21,48 \mathrm{a}$ & $5,89 \mathrm{a}$ & $11,45 \mathrm{a}$ & $3,69 \mathrm{a}$ \\
& 70 & $18,98 \mathrm{a}$ & $5,46 \mathrm{ab}$ & $8,14 \mathrm{~b}$ & $2,30 \mathrm{~b}$ \\
\hline \multirow{3}{*}{182} & 30 & $24,36 \mathrm{a}$ & $6,02 \mathrm{~b}$ & $7,60 \mathrm{a}$ & $2,81 \mathrm{a}$ \\
& 50 & $22,75 \mathrm{a}$ & $7,06 \mathrm{a}$ & $7,15 \mathrm{a}$ & $2,88 \mathrm{a}$ \\
& 70 & $18,09 \mathrm{~b}$ & $4,91 \mathrm{c}$ & $4,95 \mathrm{a}$ & $1,13 \mathrm{~b}$ \\
\hline
\end{tabular}

Médias seguidas por diferentes letras minúsculas nas colunas diferem entre si ao nível de $5 \%$ de probabilidade pelo teste Tukey.
Barbosa (1990) observou que a altura das mudas de caroba (Jacaranda copaia), também pioneira, não sofreu influências dos diferentes sombreamentos e espaçamentos testados aos seis meses em viveiro. Mas, Almeida et al. (2005), mostraram que com $30 \%$ de sombreamento mudas de Jacaranda puberula (caroba), tiveram maior crescimento em altura com 8 meses em viveiro.

Mudas de morototó (Schefflera morototoni), outra espécie pioneira, apresentaram alturas crescentes $(77,70 ; 90,00$; $97,70$; e $98,20 \mathrm{~cm})$ com o aumento do sombreamento $(0 \%$, 30, 50 e 70\%), possivelmente em conseqüência da redução de fotoassimilados e aumento do nível de auxina (Barbosa, 1985).

Porém, Scalon et al. (2003) citam que em mudas de castanha-do-maranhão (Bombacopsis glabra) a altura foi maior sob $50 \%$ de sombreamento $(22,30 \mathrm{~cm})$, seguida de $30 \%$ $(18,90 \mathrm{~cm})$ e em pleno sol $(15,80 \mathrm{~cm})$. Já nas mudas de angelim pedra (Dinizia excelsa), a altura foi maior nos sombreamentos de 30 e $50 \%$ em relaçáo a 70\% (Varela e Santos, 1992), embora essa espécie não seja pioneira.

No entanto, em mudas de Caesalpinia ferrea, o tratamento a pleno sol com 78,60 cm de altura foi maior em relação aos tramentos sob sombra natural $(13,40 \mathrm{~cm}), 50 \%(61,96 \mathrm{~cm})$ e $70 \%(68,10 \mathrm{~cm})$ de sombra em vieiro (Lima et al., 2008).

$\mathrm{O}$ diâmetro, número de folhas e área foliar também apresentaram os menores valores nas mudas em pleno sol $(0 \%$ de sombreamento) aos 57 dias, possivelmente como resultado do intenso ataque das lagartas nesse tratamento (Tabela 1). O diâmetro também foi menor no sombreamento $70 \%$ do que em 30\% nesse período, evidenciando uma alocação dos assimilados para o maior crescimento em altura em valor absoluto (Tabela 1).

No intervalo dos 139 aos 182 dias o diâmetro teve os maiores valores no sombreamento de 50\% (Tabela 1). Em mudas de fedegoso (Senna macranthera) sob 50\% de sombreamento, ocorreu aumento do diâmetro do colo em função do aumento do período de sombreamento (Chaves e Paiva, 2004). Barbosa (1990) e Almeida et al. 2005, estudaram Jacaranda copaia e Jacaranda puberula, respectivamente e verificaram que o diâmetro do colo em $70 \%$ de sombreamento foi menor do que em $0 \%, 30 \%$ e $50 \%$.

O diâmetro do colo de mudas de Caesalpinia ferrea, outra espécie pioneira foi maior a pleno sol, alcançando $4,56 \mathrm{~mm}$ (Lima et al., 2008).

As mudas de jacareúba Calophyllum angulare, aos 150 dias, não apresentaram diferenças no diâmetro do colo em $30 \%, 50 \%$ e $70 \%$, sendo que foram maiores do que em $0 \%$ de sombreamento (Muroya et al., 1997).

O número de folhas e a área foliar no início do experimento ( 57 dias) foram menores no tratamento a $0 \%$ de sombreamento 
(Tabela 1). Pois, essas partes da planta foram principalmente atacadas pelas lagartas que cortaram parcial ou totalmente as folhas nesse tratamento. Nos outros canteiros, o número de folhas diminuiu com o maior sombreamento, mas sem apresentar diferenças significativas no final do experimento (Tabela 1). Aos 182 dias, a área foliar foi maior nos menores sombreamentos (30\% e 50\%) (Tabela 1). Esses resultados mostram que os menores sombreamentos aumentaram a área foliar mantendo o número de folhas.

Em mudas de taxi-branco (Sclerolobium paniculatum) o número de folhas foi maior nos níveis $0 \%$ e 50\%, aos 16 e 18 meses, alcançando respectivamente 5,60 e 4,50 folhas, enquanto que, os níveis $70 \%$ e $90 \%$ alcançaram os menores valores 4,31 e 3,59 nesses mesmos períodos (Felfili et al., 1999).

Em mudas de Jacaranda copaia a área foliar não foi influenciada pelo fator sombra, porém aos 180 dias observouse que o nível de $30 \%$ revelou diferença entre os espaçamentos $(10 \mathrm{x} 10 \mathrm{~cm} ; 14 \mathrm{x} 14 \mathrm{~cm}$ e $18 \times 18 \mathrm{~cm})$, alcançando $3,00 \mathrm{dm}^{2} \mathrm{em}$ $14 \times 14 \mathrm{~cm}$ valor superior aos demais (Barbosa, 1990). Para a espécie Bombacopsis glabra também não ocorreu diferença entre os tratamentos de luminosidade (Scalon et al., 2003).

No estudo de Almeida et al. (2005) mudas de Jacaranda puberula apresentaram maior crescimento, inclusive em área foliar, quando cultivadas sob $30 \%$ de sombreamento, mostrando-se $70 \%$ de sombra nas condiçôes de viveiro estudada ser prejudicial ao crescimento dessas mudas. Enquanto que em mudas de sumaúma (Ceiba pentandra), cedrorana (Cedrelinga catenaeformis) e Calophyllum angulare cultivas em viveiro sob diferentes sombreamentos, apresentaram maior área foliar sob $70 \%$ de sombra, resultados apresentados nos estudos de Pedroso e Varela (1995); Farias et al. (1997) e Muroya et al. (1997), respectivamente.

Mudas da regeneração natural do banco de mudas, sob o dossel da floresta com maior sombreamento, tem o crescimento menor, chegando até a morte com o decorrer do tempo quando não há abertura de clareira. A adaptação das espécies à luminosidade ambiental é importante principalmente na fase juvenil por condicionar mudanças morfogenéticas e fisiológicas na sua estrutura e função (Whatley e Whatley, 1982 citado por Engel e Poggiani, 1990), determinando o sucesso ou não da regeneração (Engel e Poggiani, 1990).

A relação altura total/diâmetro do colo (HT/DC) nas mudas com $50 \%$ de poda foi maior do que com $75 \%$, no sombreamento de $70 \%$ no final do experimento. O valor médio dos tratamentos com poda nos sombreamentos de $30 \%$ e 70\% foram maiores do que a do 50\% (Tabela 2).

Considerando que a relação HT/DC exprime o equilíbrio de desenvolvimento das mudas em viveiro (Carneiro, 1995) o valor médio do sombreamento $50 \%(3,205)$ mostra que o diâmetro teve o crescimento mais estimulado do que a altura
(Tabela 2). Essa afirmativa está corroborada nos dados da Tabela 1 na avaliaçáo aos 182 dias, onde o valor do diâmetro em $50 \%$ de sombreamento foi maior do que em $30 \%$ e $70 \%$.

Os valores recomendados para a relação HT/DC é de 5,4 a 8,1 em Pinus taeda (Carneiro,1995).

Em mudas de Senna macranthera foi encontrado o valor de 4,07, aos 150 dias e sob $50 \%$ de sombreamento (Chaves e Paiva, 2004).

Segundo Birchler et al. (1998), em Quercus ilex o valor variou de 7 a 10. Quanto menor o valor desse parâmetro de qualidade de mudas, maior será a capacidade das mudas sobreviverem e se estabelecerem na área do plantio definitivo (Carneiro, 1983 citado por Cruz et al., 2006).

Em mudas de crindiúva (Trema micrantha), aos 90 e aos 120 dias, as mudas crescidas com 45 e 60 dias e com 45, 60 e 75 dias sob sombreamento, respectivamente, apresentaram valores da relação da altura da parte aérea/diâmetro do coleto inferior a 8 (Fonseca et al., 2002).

A diferença da relaçáo HT/DC entre os níveis de 50\% e $75 \%$ sob $70 \%$ de sombreamento (Tabela 2) não foi considerada, pois as mudas tiveram os menores valores nas outras variáveis estudadas, exceção no número de folhas aos 182 dias (Tabelas 1 e 3 ).

Os menores valores nas variáveis da produção de matéria seca mostram que no sombreamento de $70 \%$ pode ter ocorrido uma redução da capacidade fotossintética afetando o crescimento das mudas de marupá.

Os efeitos dos diferentes níveis de poda de raiz não foram significativos nos pesos da matéria seca de raiz, caule, folha e total e no Índice de Qualidade de Dickson (IQD).

No entanto, os valores médios dessas variáveis e parâmetros, nos sombreamentos de $30 \%$ e $50 \%$, foram maiores do que em 70\% (Tabela 3).

O valor mínimo indicado do IQD para mudas produzidas em tubetes de 50 a $60 \mathrm{~cm}^{3}$ é de 0,20, segundo Hunt (1990) citado por Chaves e Paiva (2004).

As mudas de marupá tiveram os valores superiores a esse mínimo, especialmente nos sombreamento de $30 \%$ e $50 \%$, mas produzida em sacos plásticos (Tabela 3). Entretanto, devese considerar os valores obtidos para cada espécie, condiçóes ambientais de cultivo e a afirmativa de Gomes (2001) citado por Cruz et al. (2006) que quanto maior for o valor melhor será o padrão de qualidade.

O maior IQD encontrado em mudas de Senna macranthera foi de 3,36 aos 150 dias após a semeadura (Chaves e Paiva, 2004). Em mudas de Schinus terebinthifolius o maior índice foi de 0,73 , cultivada em tubete de $150 \mathrm{~cm}^{3}$ e na densidade de 108 mudas $/ \mathrm{m}^{2}$ (José et al., 2005). 
Tabela 2 - Médias da relação altura total/diâmetro do colo (HT/DC) das mudas de Marupá (Simarouba amara Aubl.- Simaroubaceae) sob diferentes níveis de sombreamento e poda de raiz.

\begin{tabular}{|c|c|c|c|c|c|c|}
\hline \multirow{2}{*}{ Dias no viveiro } & \multirow{2}{*}{ Sombra (\%) } & \multicolumn{4}{|c|}{ Poda } & \multirow{2}{*}{ Média } \\
\hline & & $0 \%$ & $25 \%$ & $50 \%$ & $75 \%$ & \\
\hline \multirow{4}{*}{182} & 30 & 4,512 a $A$ & 3,508 a $A$ & 4,172 a $A$ & 4,144 a A & $4,084 \mathrm{~A}$ \\
\hline & 50 & 3,496 a B & 3,520 a A & 3,022 a B & 2,782 a B & $3,205 B$ \\
\hline & 70 & $3,714 a b A B$ & $3,682 \mathrm{ab} A$ & 4,636 a $A$ & 3,078 b B & $3,778 \mathrm{~A}$ \\
\hline & Média & $3,907 \mathrm{a}$ & $3,570 \mathrm{a}$ & $3,943 \mathrm{a}$ & $3,335 \mathrm{a}$ & - \\
\hline
\end{tabular}

Médias seguidas por letras distintas maiúscula nas colunas e minúsculas nas linhas diferem entre si no nível de $5 \%$ de probabilidade pelo Teste Tukey.

Tabela 3 - Valores médios do peso da matéria seca da raiz, caule, folha e total (g) e o Índice de Qualidade de Dickson (IQD) das mudas de marupá (Simarouba amara Aubl.- Simaroubaceae) cultivadas sob diferentes níveis de sombreamento.

\begin{tabular}{|c|c|c|c|c|c|c|}
\hline \multirow{2}{*}{ Dias no viveiro } & \multirow{2}{*}{ Sombra (\%) } & \multicolumn{4}{|c|}{ Peso da matéria seca (g) } & \multirow{2}{*}{ IQD } \\
\hline & & Raiz & Caule & Folha & Total & \\
\hline \multirow{3}{*}{182} & 30 & $0,926 \mathrm{a}$ & $1,216 a$ & $1,921 \mathrm{a}$ & $4,063 \mathrm{a}$ & $0,543 a$ \\
\hline & 50 & $1,083 \mathrm{a}$ & $1,454 \mathrm{a}$ & $1,950 \mathrm{a}$ & $4,243 \mathrm{a}$ & $0,691 \mathrm{a}$ \\
\hline & 70 & $0,394 \mathrm{~b}$ & $0,603 b$ & $0,604 \mathrm{~b}$ & $1,601 \mathrm{~b}$ & $0,232 b$ \\
\hline
\end{tabular}

Médias seguidas por letras diferentes nas colunas diferem entre si ao nível de $5 \%$ de probabilidade pelo teste Tukey.

A qualidade das mudas foi influenciada pelos sombreamentos testados e tiveram os maiores IQDs nos níveis de $30 \%$ e $50 \%$, mas com maior equilíbrio de crescimento no nível de $50 \%$ encontrado através da relação altura/diâmetro do coleto (Tabela 3).

O índice de qualidade de Dickson é um bom indicador da qualidade das mudas, pois é considerado o vigor e o equilíbrio da distribuição da biomassa na muda. $\mathrm{O}$ índice pondera os resultados de muitas variáveis. As variáveis morfológicas e os índices utilizados para avaliação da qualidade das mudas podem ser utilizados isoladamente ou em conjunto, para classificação do padráo da qualidade de mudas, desde que sejam empregados em mudas desenvolvidas em condiçóes de ambiente semelhantes (Fonseca et al., 2002).

As mudas de marupá mostraram resistência às podas de raiz, indicada pela ausência de diferenças de crescimento da parte aérea em todos os níveis e períodos avaliados, evidenciando recuperação suficiente do sistema radicular podado para manter o crescimento e a tendência da espécie (pioneira) exigir menos sombreamento para um maior crescimento à medida que se estabelece em viveiro até 6 meses.

\section{CONCLUSÕES}

As mudas de marupá cultivadas em viveiro e sem proteção dos canteiros estáo sujeitas ao ataque de lagartas que se alimentam das folhas destruindo completamente a planta nos primeiros dois meses.

Nos canteiros com proteção de sombrite a sobrevivência foi superior a $83 \%$ e sem ataque de lagartas.

As mudas de marupá resistiram aos níveis de poda testados e evidenciaram recuperação suficiente do sistema radicular podado para manter o crescimento sem diferenças das mudas não podadas.

As mudas de marupá avaliadas aos 182 dias no viveiro apresentaram maior qualidade para plantios e com maior equilíbrio de crescimento no sombreamento de $50 \%$.

Foi possível obter mudas de Simarouba amara Aubl., com médias de $22,75 \mathrm{~cm}$ de altura e 7,06 $\mathrm{mm}$ de diâmetro de coleto, quando submetidas a $50 \%$ de sombreamento, num período de 182 dias.

\section{AGRADECIMENTOS}

Ao Instituto Nacional de Pesquisas da Amazônia/ Coordenação de Pesquisas em Silvicultura Tropical e ao Conselho Nacional de Desenvolvimento Científico e Tecnológico - Grupo de Pesquisas "Silvicultura de espécies florestais nativas da Amazônia”. 


\section{BIBLIOGRAFIA CITADA}

Almeida, L.S.; Maia.N.; Ortega, A.R.; Angelo, A.C. 2005. Crescimento de mudas de Jacaranda puberula Cham. em viveiro submetidas a diferentes níveis de luminosidade. Ciência Florestal, 15: $323-329$.

Alvarenga, R.C.; Barros, N.F.; Dantas, C.E.S.; Lobão, D. 1994. Efeito do conteúdo de água no solo e da poda de raízes sobre o crescimento de mudas de Eucalipto. Revista Árvore, 18: 107 $-114$.

Barbosa, A.P. 1985. Ecofisiologia do crescimento inicial de mudas de morototó (Schefflera morototoni, Aubl. Frondim - Araliaceae) cultivadas sob quatro niveis de radiação solar e três niveis de espaçamento. Dissertaçáo de Mestrado, Instituto Nacional de Pesquisas da Amazônia, Manaus, Amazonas. 95 pp.

Barbosa, A.P. 1990. O crescimento de mudas de caroba (Jacaranda copaia Aubl. D. Don. - Bignoniaceae) cultivadas sob diferentes níveis de sombreamento e espaçamento. Anais do $6^{\circ}$ Congresso Florestal Brasileiro, Campos do Jordão - São Paulo, v. 3, p. 526-534.

Barbosa, A.P.; Uchida, T.; Campos, M.A.; Marques, A.S.J. 1998. Tecnologia de produção de mudas de espécies florestais. In: Higuchi,N; Campos, M. A. A; Sampaio, P. T. B; Santos, J. Pesquisas florestais para a conservação da floresta e reabilitação de áreas degradadas da Amazônia. Espaço Comunicação Ltda. Manaus: UA, cap. 12, p. 215-252.

Barroso, D.G.; Carneiro, J. G. A.; Leles, P. S. S.; Morgado, I. F. 2000. Regeneração de raízes de mudas de Eucalipto em recipientes e substratos. Scientia Agrícola, Piracicaba, São Paulo, v. 57, n. 2, p. 229-237.

Birchler, T.; Rose, R.W.; Royo, A.; Pardos, M. 1998. La planta ideal: revision del concepto, parametros definitorios e implementacion practica. Investigacion Agrária, Sistemas y Recursos Forestales 7:109-121.

Campos, M.A.A.; Uchida, T. 2002. Influência do sombreamento no crescimento de mudas de três espécies amazônicas. Pesquisa Agropecuária Brasileira, 37: 281-288.

Carneiro, J.G.A. 1983. Variações na metodologia de produção de mudas florestais afetam os parâmetros morfo-fisiológicos que indicam qualidade. FUPEF. Série Técnica, n. 12. Curitiba, PR. Apud Cruz, C.A.F.; Nogueira, H.P.; Guerreiro, C.R.A. 2006. Efeito da adubação nitrogenada na produção de sete-cascas (Samanaea inopinata (Harms) Ducke). Revista Árvore, 30: 537-546.

Carneiro, J.G.A. 1995. Produção e controle de qualidade de mudas florestais. Curitiba: Universidade Federal do Paraná: Campos dos Goytacazes: Universidade Estadual do Norte Fluminense. $451 \mathrm{pp}$.

Cavalcante, L.C. 2006. Avaliação de novas espécies madeireiras na fabricação do cajón. Monografia, Universidade de Brasília, Brasília. 35 pp.

Chaves, A.S. e Paiva, H.N. 2004. Influência de diferentes períodos de sombreamento. Scientia Forestalis, 65: 22-29.

Costa, L.C.B.; Rocha, E.A.; Silva, L.A.M.; Jardim, J.G.; Silva, D.C.; Gaião, L.O.; Moreira, R.C.T. 2006. Levantamento preliminar das espécies vegetais com potencial econômico no Parque Municipal da Boa Esperança, Ilhéus, Bahia, Brasil. Acta Farmacéutica Bonaerense, 25: 184-91.

Cruz, C.A.F.; Paiva, H.N.; Guerrero, C.R.A. 2006. Efeito da adubação nitrogenada na produção de mudas de sete-cacas (Samanea inopinata (Harms) Ducke). Revista Árvore, 30: 537 $-546$.

Dickson, A.; Leaf, A. L.; Hosner, J. F. 1960. Quality appraisal of white spruce and white pine seedling stock in nurseries. Forestry Chronicle, 36: 10-13 Apud Fonseca, E.P. 2000. Padrão de qualidade de mudas de Trema micantra (L.) Blume, Cedrela fissilis Vell. e Aspisdosperma polyneurom Müll. Arg. produzidas sob diferentes períodos de sombreamento. Tese (Doutorado em Agronomia - Produçâo Vegetal). Universidade Estadual Paulista. 113 pp.

Freitas, T.A.S.; Barroso, D.G.; Souza, L.S.; Carneiro, J.G.A. 2009. Efeito da poda de raízes sobre o crescimento das mudas de Eucalipto. Ciência Florestal, 19: 1 - 6.

Engel, V.L e Poggiani, F. 1990. Influência do sombreamento sobre o crescimento de mudas de algumas essencias nativas e suas implicaçóes ecológicas e silviculturais. Instituto de Pesquisas e Estudos Florestais, 43/44: 1 - 10.

Farias, V.C.C.; Costa, S.S.; Batalha, L.F.P. 1997. Análise de crescimento de mudas de cedrorana (Cedrelinga catenaeformis (Ducke) Ducke) cultivadas em condiçôes de viveiro. Revista Brasileira de Sementes, 19: 192 - 199

Felfili, J.M.; Hilgbert, L.F.; Franco, A.C.; Sousa-Silva, J.C.; Resende, A.V.; Nogueira, M.V.P. 1999. Comportamento de plântulas de Sclerolobium paniculatum Vog. var. rubiginosum (Tul.) Benth. sob diferentes níveis de sombreamento, em viveiro. Revista Brasileira de Botânica, 22: 297-301.

Fonseca, E.P.; Valéri, S.V.; Miglioranza, E.; Fonseca, N.A.N.; Couto, L. 2002. Padrão de qualidade de mudas de Trema micranta (L.) Blume, produzidas sob diferentes períodos de sombreamento. Revista Arvore, 26: 515 - 523.

Franke, I.L. 1999. Principais usos e serviços de árvores e arbustos promissores que ocorrem em pastagens no Estado do Acre. Embrapa, Comunicado Técnico, 106: 1-6.

Gomes, J.M. 2001. Parâmetros morfológicos na avaliação da qualidade de mudas de Eucalyptus grandis, produzidas em diferentes tamanhos de tubete e de dosagens de N-P-K. p. 126. Tese (Doutorado em Ciência Florestal). Universidade Federal de Viçosa, Viçosa, 2001. Apud Cruz, C.A.F.; Nogueira, H.P. Guerreiro, C.R.A. 2006. Efeito da adubação nitrogenada na produção de sete-cascas (Samanaea inopinata (Harms) Ducke). Revista Árvore, 30: 537-546.

Hunt, G.A. 1990. Effect of styroblock design and Cooper treatment on morphology of conifer seedlings. In Target seedlings symposium, meeting of the Western Forest Nursery Associations, Roseburg, Proceedings. Fort Collins: United States Department of Agriculture, Forest Service, p. 218 - 222. Apud Chaves, A.S. e Paiva, H.N. 2004. Influência de diferentes períodos de sombreamento sobre a qualidade de mudas de fedegoso (Senna macranthera (Collad.) Irwin et Barn.). Scientia Forestalis, 65: $22-29$ 
Instituto Brasileiro de Desenvolvimento Florestal - IBDF. 1983. Potencial madeireiro do Grande Carajás. IBDF/LPF, Brasília, $134 \mathrm{pp}$

José, A.C.; Davide, A.C.; Oliveira, S.L. 2005. Produçâo de mudas de aroeira (Schinus terebinthifolius Raddi) para recuperação de áreas degradadas pela mineração de bauxita. Cerne, 11: 187-196.

Lima, J.D.; Silva, B.M.S.; Moraes, W.S.; Dantas, V.A.V.; Almeida, C.C. 2008. Efeitos da luminosidade no crescimento de mudas de Caesalpinia ferrea Mart. Ex Tul. (Leguminosae, Caesalpinoideae). Acta Amazonica, 38: 5-10.

Loureiro, A.A.; Silva, M.F.; Alencar, J.C. 1979. Essências madeireiras da Amazônia. Instituto Nacional de Pesquisas da Amzônia, INPA/SUFRAMA-MA. Manaus, AM, v.I. 245 pp.

Marques, M.H.B.; Martins, V.A.; Souza, M.R.; Marcus, V.S.A. 2006. Efeito da secagem nas propriedades acústicas da madeira de marupá (Simarouba amara Aubl.). Floresta \& Ambiente, 12: 57-64.

Muroya, K.; Varela, V.P.; Campos, M.A.A. 1997. Análise de crescimento de mudas de jacareúba (Calophyllum angulare A. C. Smith - Guttiferae) cultivadas em condiçôes de viveiro. Acta Amazonica, 27: 197-212.

Novaes, A. B.; Carneiro, J.G.A.; Barroso, D.G.; Leles, P.S.S. 2002. Avaliação do potencial de regeneração de raízes de mudas de Pinus taeda L., produzidas em diferentes tipos de recipientes, e o seu desempenho no campo. Revista Árvore, 26: 6.

Pedroso, S. G. e Varela, V. P. 1995. Efeito do sombreamento em mudas de sumaúma (Ceiba pentandra (E.) Gaertn). Revista Brasileira de Sementes, 17: 47-51.

Pinto, A.M.; Ribeiro, R.J.; Alencar, J.C.; Barbosa, A.P. 2005. Fenologia de Simarouba amara Aubl. na Reserva Florestal Adolpho Ducke, Manaus, AM. Acta Amazonica, 35: 347 352.

Ranzani, G. 1980. Identificação e caracterização de alguns solos da Estação Experimental de Silvicultura Tropical do INPA. Acta Amazonica, 10: 7-41.
Scalon, S.P.Q.; Mussuri, R.M.; Rigoni, M.R.; Scalon Filho, H. 2003. Crescimento inicial de mudas de Bombacopsis glabra (Past.) A. Robyns sob condiçôes de sombreamento. Revista Árvore, 27: 753-758.

Slooten, H.J. van der; Souza, M.R. de. 1993. Avaliação das espécies madeireiras da Amazônia selecionadas para a manufatura de instrumentos musicais. Instituto Nacional de Pesquisas da Amazônia, Manaus, 123 pp.

Souza, G. L. F. M.; Ribeiro, M.C.C.; Cardoso, E.A.; Pires, G.S.; Souza, P.A. 2006. Efeito da época de poda do sistema radicular no crescimento de mudas de algarobeira. Revista Caatinga, 19: $250-254$.

Souza, M. H. 1997. Madeiras tropicais brasileiras. IBAMA/LPF, Brasília, 152 pp.

Uchida, T. e Campos, M.A.A. 2000. Influência do sombreamenbto no crescimento de mudas de cumaru (Dipteryx odorata (Aubl.) Willd. - Fabaceae), cultivadas em viveiro. Acta Amazônica, 30: 107-114.

Varela, V.P.; Santos, J. 1992. Influência do sombreamento na produção de mudas de Angelim pedra (Dinizia excelsa Ducke). Acta Amazonica, 22: 407-411.

Whatley, J.M. e Whatley, F.R. 1982. A luz e a vida das plantas. EPU/EDUSP, São Paulo, 101 p. Apud Engel, V.L e Poggiani, F. 1990. Influência do sombreamento sobre o crescimento de mudas de algumas essências nativas e suas implicações ecológicas e silviculturais. IPEF, Piracicaba, SP, n. 43/44, p. 1 - 10.

Recebido em 17/12/2008

Aceite em 21/09/2009 